Filming in the home: $A$

reflexive account of

microethnographic data

collection with family

caregivers of older adults

\section{Marjorie Silverman}

School of Social Work, University of Ottawa, Ottawa, Ontario, Canada
2016, Vol. 15(4) 570-584

(C) The Author(s) 2015

Reprints and permissions:

sagepub.co.uk/journalsPermissions.nav

DOI: I0.1 I77/I4733250I55957/2

qsw.sagepub.com

\begin{abstract}
This article explores the impact of the researcher's reflexivity on the data collection and analysis process in the context of a videographic study of home-based family caregivers of older adults. Going beyond a discussion of the role of the researcher's subjectivity, the article builds on current literature by exploring how the researcher's embodied selfreflexivity can be used to enrich video based research. The article addresses the researcher's personal social location and shifting roles throughout the study and how these impacted on her work with the camera, her moment to moment ethical decisions and her perceptions of the participants' realities. The author illustrates, through the use of journal and transcript excerpts, how the dynamic relationship between the researcher, the participants and the camera creates overlapping and complementary layers of information that together form a cohesive portrait of the action. Throughout, the article discusses the contribution of reflexivity to both the creation and resolution of ethical tensions in the research space.
\end{abstract}

\title{
Keywords
}

Family caregiving, older adults, visual methods, ageing, home, ethnography

This article recounts my personal journey conducting videographic data collection in residential home settings. It addresses the impact of my social location on the development and implementation of a video based research study, and how my

\section{Corresponding author:}

Marjorie Silverman, School of Social Work, University of Ottawa, 120 University, Office I2044, Ottawa, Ontario, Canada KIN 6N5.

Email: marjorie.silverman@uOttawa.ca 
decisions and presence during the filming were central to the creation of the research space and the findings that emerged from the project. Although video data collection and the analysis of social interactions in natural settings have become increasingly popular in the social sciences (Knoblauch and Schnettler, 2012), there is a lack of literature discussing the lived experience of conducting videographic research (Luff and Heath, 2012). This article aims to fill that gap by discussing my experiences during videographic data collection in the context of a specific project, as well as how these experiences shaped, and were in turn shaped by, a myriad of subjective and relational factors. The primary focus of the article is on the interactions between the camera, the researcher and the participants, as well as the ethical tensions to which these interactions gave rise and the impacts on the knowledge creation process.

\section{Background}

The past decade has seen a turn in the social sciences towards the use of video and other multimedia methods as providing ways of accessing embodiment, movement and the multi-sensory elements of the research environment (Hurdley and Dicks, 2011; Pink, 2015, 2011). The increasing interest in video data collection and analysis has led to the development of practical procedures regarding the design and implementation of video based research projects (Heath et al., 2010) as well as the sequential analysis of talk and images (Knoblauch and Schnettler, 2012). It has also led to an evolving awareness of the importance of the researcher's own embodied subjectivity to every aspect of the research process. For example, Mondada (2006) describes filming as an embodied exercise, arguing that the researcher's movements, technical choices and perspectives are embedded in the entirety of the process. Similarly, Pink $(2007,2012)$ explores how the researcher's embodied and situated presence is intrinsic to the creation of each scene of action, and Knoblauch and Tuma (2011) and Knoblauch and Schnettler (2012) describe how situations captured by the camera are influenced by numerous nonvisual factors such as smell and temperature that only the presence of the researcher can discern.

Complementing discussions regarding the impact of the researcher's subjectivity on the research process is scholarship addressing the importance of the position of the researcher within the context being studied. Mannay (2010) discusses the advantages and challenges of being positioned as either an insider or outsider in the research context. As she conducts fieldwork in her own community, she worries about being caught in common and taken-for-granted understandings. Similarly, Richardson (2013) explores how his own masculinity led to projections and assumptions on the part of the male participants in his research. Both Mannay (2010) and Richardson (2013) turn to visual images as a way of seeing their participants in a new light that is unencumbered by insider assumptions. In bringing forth new angles, visual images help to 'make the familiar strange' (Mannay, 2010). Lomax et al. (2011) also argues for the advantages of images - in this case 
participant driven video - in making visible the multiple aspects of the participants' characteristics and personalities, including performed identities.

Despite the wider interest in the link between the researcher's subjectivity and positioning and visual data collection, to date there is a lack of literature describing the personal lived experience of filming and how the researcher can use that lived experience to further the goals of the study. In describing how I operationalized a microethnographic study involving the home-based filming of family caregivers of older adults, I provide a personal voice from the field that elucidates how subjectivity can be used as a research tool. I address, from a self-reflexive position, the experience of being both behind and in front of the camera and how these locations corresponded with my shifting positions as researcher, professional, doctoral student and observer. Through the kaleidoscope of these shifting positions, I argue that we can use lived experiences to enrich understanding of the research subjects and our overall findings. I include journal entries and personal reflections throughout the article to offer concrete examples of the types of self-reflection that influenced the project. These examples also highlight the various layers of information that emerged throughout the data collection phase - the actual scene as it was occurring, what the camera captured of the scene, and my own memories and reactions to the scene. Throughout, I address the ethical tensions that arose in part by my self-reflexive stance. In sum, the article provides a portrait of how our own everyday lives as researchers can be used as enriching tools when filming the everyday lives of others.

\section{Description of the study}

The project described in this article sought to explore how women caregivers' movements and actions recount their lived experience of care provision. My intent was to explore what women caregivers' expressions and actions reveal about care to older adults, with the goals of validating the importance of their subjective everyday reality of care, as well as helping practitioners view the body as an entry point toward a more comprehensive vision of caregivers' realities. The study aimed to access the intimate, immediate experiences of care in the home setting, and to reveal potential contradictions between these lived realities and the pressures and expectations of the health and social service system (for a detailed account of the study and its findings as well as its contribution to clinical practice, see Silverman, 2013, 2015).

It was the nonverbal, embodied aspect of the research that led me to seek out visual methods and in particular a microethnographic approach. Microethnography, which favours the recording and analysing of the detailed, embodied aspects of daily life, aims to address macro social issues through the micro analysis of naturally occurring activity (Streeck and Mehus, 2005). Different than visual ethnography which does not necessarily involve the same preoccupation with moment-to-moment interactions, microethnography aims to provide a complex understanding of small, seemingly mundane scenes of everyday life 
(Erickson, 1996; LeBaron, 2008). I aimed to capture caregivers' activities in real time (Erickson, 1996), using an approach that examined both verbal and nonverbal action such as gesture, facial expression, gaze and posture (Mondada, 2006; Streeck et al., 2011; Stivers and Sidnell, 2005).

Following the microethnographic tradition of keeping sample sizes small due to the in-depth nature of the approach and the fact that microethnographic research does not claim to derive generalized conclusions (Erickson, 1996; LeBaron, 2008), I recruited five women family caregivers, all co-residing with care receivers. Lillian, Susan, Marie and Bonnie were caring for a spouse and Rebecca was caring for a parent (all names have been changed to protect confidentiality). The caregivers ranged in age from 48 to 63 , and the care receivers from 60 to 82 . The care receivers were suffering from a variety of advanced-stage illnesses, including Parkinson's, Crohn's, early dementia, cardiovascular problems and partial paralysis. Two of the care receivers passed away during the course of the research, a challenge which I describe below.

I recruited the participants through a Health and Social Service Centre in Montreal, Canada with a large population of older adults and which specializes in gerontological services. I was familiar with the Centre in which I was recruiting, as I had worked there for many years. I was able to speak to individual practitioners, attend staff meetings, distribute pamphlets describing the project and follow up with phone calls and on-site visits. Despite these efforts, the recruitment proved difficult due to the visual nature of the project. Many caregivers referred by their practitioners expressed discomfort at the idea of being filmed and declined to participate. The fact that both the caregiver and care receiver had to consent to participate presented an additional challenge. It took approximately one year of solicitation to secure the five participant dyads. The dyads that ultimately agreed to participate viewed the project as a way to make a contribution to research and to practice, as they had all experienced inadequacies in the support they received in the health and social service system. This raises the question as to whether these advocacy-driven participants were 'typical' caregiver dyads. Yet since the goal of microethnography is not to derive general conclusions based on a typical population, but to examine each situation as a unique case study (Erickson, 1996; LeBaron, 2008), I did not view this as an impediment.

I chose to film caregivers in their homes as it remains a less examined site of caregiving. While it is customary to see caregivers in public settings such as doctors' offices and long-term care institutions, it is rare that we witness their intimate care moments in the home - a private moment of tears, or a joyful moment of laughter. There exists only a handful of recent studies that have employed videography in home settings (Campos et al., 2009; Ochs and Kremier-Sadlick, 2013; Saxbe and Repetti, 2008). Within the field of social gerontology more specifically, video based research has primarily occurred outside the home, in settings as diverse as care-based hair salons (Ward and Campbell, 2013) and long-term care institutions (Intrieri and Morse, 1997). Yet due to the particular symbolism, meaning, and history of home spaces (England and Dyck, 
2011), filming in the home offers a unique opportunity to capture the intimacies of everyday life. As expressed by Ochs and Kremier-Sadlick (2013), home-based filming allows researchers to bridge the gap that normally protects the privacy of the family home as sacrosanct.

I conducted between two and six visits with each dyad over the course of one to five months, between April and December 2011. The variation in the number of home visits was due directly to the deaths of two care recipients. During each visit, I observed and filmed for approximately $1 \mathrm{~h}$. I intentionally conducted the visits at different times of day, in part to witness variations in routines and interactions, as well as to diminish the pressure to capture a high quality of footage during each visit (Heath et al., 2010). While video was the principal means of data collection, additional forms of fieldwork were an important component of the research. Following the recruitment of each new caregiver, I scheduled an un-filmed meeting to obtain an overview of the history and nature of the caregiving situation. After each visit, I kept a journal of field notes in which I recorded my impressions, perceptions and associations, as well as observations pertaining to the concrete environment such as conversations, noises or smells (Lofland and Lofland, 1995). These field notes assisted with the analysis and helped clarify my visceral feelings and thoughts. Rather than crowding the research field with too many tools (Mannay and Morgan, 2014), these additional strategies complemented the images produced by the camera.

The project adhered to Canadian Tri-council guidelines (Canada Public Works and Government Services, 2005) and I achieved research validity and trustworthiness through a variety of means, including peer de-briefing (Padgett, 2008). In addition, the empirical nature of the videographic data ensured that footage could be scrutinized (LeBaron, 2008) and my prolonged engagement in the field led me to build trust with the participants and to understand their lives more fully (Lincoln and Guba, 1985).

\section{Self-reflexivity}

Numerous aspects of my personal social location impacted on the research process. The most determining factor that shaped my experiences throughout the study was becoming a parent. A few months prior to beginning the recruitment, I became a mother. Giving birth and caring for my newborn made me aware of my embodiment in new ways. I was struck by the physicality of parenting - the holding, the carrying, the equipment, the lifting and the bodily fluids. My posture changed, my fatigue level augmented and my body was in constant motion. I also noticed the emotional labour in my voice, as I spoke to my baby gently or enthusiastically, even when fatigued or irritated. These experiences heightened my sense of empathy for the caregiver participants, who were confronted constantly with physical and emotional demands in a context of illness, decline and loss. This led to a greater sensitivity on my part when analysing the nonverbal data as I was able to viscerally empathize with some of their movements and gestures. 
I was also acutely aware of the impact that other aspects of my social location had on the filming and analysis. For example, although I had worked with caregivers for many years, I had never been a caregiver to an older adult with a chronic illness or disability. This led me to imagine that some caregivers might see me as a professional with whom they could speak, yet at the same time skeptical of my ability to capture their reality. Similarly, my status as both a student-researcher as well as a professional psychosocial practitioner led to the same mix of comfort and hesitancy that carried through into the filming process. Further to juggling my roles as a novice researcher, professional and doctoral student, the intimacy of the inhome filming compelled me to reflect on the other aspects of my identity that were either in harmony or in juxtaposition to those of the participants. In particular, I embodied many markers of privilege - young, healthy, white, middle class, educated - that I anticipated might distance me from the participants, many of whom were struggling financially and all of whom were living with precarious health challenges. Yet through the course of conversations with the caregivers, I also sensed that my identity as a woman and mother contributed to a sense of greater comfort on their part. They often made allusion to these particular aspects of my social location, asking me about my son and seeking common points of understanding. Finding points of commonality seemed to be a way for the caregivers to transform me from an 'intruder' into a friendly visitor. It may also speak to the social performance pressure they felt as they found themselves on the front stage (Goffman, 1959 ) in front of a camera, despite being in the intimacy of their own home.

While these points of commonality between myself and the caregivers assisted in establishing a trust that in turn facilitated ongoing ethical consent (Gabb, 2010), it also led me to question the impact of my positionality as both insider and outsider on my moment to moment filming decisions. Did commonalities lead me to assume what the caregivers might find embarrassing or uncomfortable? Or did differences lead me to assume that they would not want an 'intruder' witnessing their intimate moments? As I illustrate below, my shifting positions as both insider and outsider had concrete impacts on the data collection and analysis.

\section{Behind the camera}

When the filming sessions began, I had not discussed with the dyads in advance whether there were areas of the home that they did not want me to film or certain activities that they did not want me to witness. This stemmed in part from my wish to let the action unfold as naturally as possible without predetermined limits, and in part from implicit assumptions regarding the boundaries of the filming (for example, I had taken for granted that I would not be filming nudity). However, I found myself experiencing moments of ethical discomfort, particularly when witnessing events or interactions that were highly intimate such as bodily care or tense emotional exchanges. My inner ethical boundary was in contradiction with the set goals of the project, namely to film all the action as it occurred. Could I (and should I) surpass my own discomfort for the sake of the research? Ultimately, as I 
describe below, these experiences of discomfort brought additional insight into the participants' experiences. The following journal entry describes a scene in which I chose to turn the camera away due to my own discomfort.

When I arrived this morning, one of the first things Marie did was change her husband's diaper. I made sure to be very discreet. I was standing next to the bedroom door holding the camera. I felt quite uncomfortable, like I was in their very intimate space. Jean was lying in bed wearing only a diaper. Marie helped him stand up and pulled down his diaper. I could see him naked from behind. I would have liked to get more footage but I just couldn't. I turned the camera away. (Journal notes, 21 November 2011).

In the scene described above, my unease had a direct impact on the filming as it led me to move the camera, thus missing key footage. At other times, my discomfort led me to retreat behind the professional stance of the camera. By focusing on the lens, the buttons, or on getting the right shot, I could temporarily deflect my gaze from the action while the camera did the looking on my behalf. In this sense, the camera allowed for the mitigation of relationships (Pink, 2007), either bringing me closer to the participants or creating more distance. When I was not looking through the camera, the participants had a tendency to engage in conversation. When I was behind the camera, they were absorbed more fully in their everyday activities. The camera thus became, in part, a tool for communicating with the participants as well as for negotiating space, relationship and difficult material (Pink, 2007). The following journal note describes how, instead of turning the camera away from the action, I used the camera as a tool for easing my own discomfort.

When I arrived, Jean was being given a bath by a home aid worker. The bathroom door was partly open and Marie was helping the worker dry off and dress her husband. I felt unsure where to place myself, or whether or not to film. I looked down and focused my eyes on the camera. (Journal notes, 7 December 2011).

Moments such as those described above brought forward vital information about the caregivers I was studying. Although turning the camera away meant losing footage of an important scene, confronting my moral limits gave me a visceral sense of the intimacy of caregiving. It revealed the extent to which caregiving reaches into the intimacy of loss, pain, dependency, humiliation, frustration and the connections between such complex emotions and the physical, bodily dimensions of caregiving. I was not only observing the lived experience of caregiving but viscerally feeling it as well. Although there was a loss of footage, the experience increased my understanding of the lives of the participants.

The paradox of losing footage yet gaining insight highlights the fact that the researcher is always implicated in the context being studied (Knoblauch and Schnettler, 2012; Mondada, 2006) and that this implication and presence necessarily adds to knowledge creation. Although microethnography is inscribed in a tradition of naturalism that aims to describe reality with the least amount of 
disturbance (Bull, 2002; Scherer and Ekman, 1982), the researcher's presence, choices, comfort level, responses to the material being filmed, and assumptions based on insider or outsider perspectives, all affect the way the researcher collects and interprets the material. The physical presence of the camera acts as a reminder of the 'non-natural' nature of the situation and necessarily alters the way the participants respond during the data collection (many caregivers commented on the presence of the camera). Yet this same barrier can bring forth a myriad of dynamics that would otherwise go unnoticed. Without the camera, the intimacy of the interactions I was witnessing would not have been as apparent. Turning my eyes away from a scene was a subtle gesture; turning the camera away permanently recorded the magnitude of my reactions to the lived experience of caregiving.

The camera also highlighted the (often invisible) power dynamics at play between the research and the participants. Regardless of the fact that I had the participants' consent to film everything, I nonetheless chose what to film. Did I disempower the participants by turning the camera away when they had already provided informed consent? Or was I protecting them from an unspoken, yet intersubjective sense of discomfort? Would the participants have been capable of expressing unease in the context of a professional interaction? These tensions fueled the filming process, yet only fully came to light when I examined more closely my shifting positions and feelings within the research space.

\section{In front of the camera}

Being a novice videographer prior to beginning the project, my ideas about filming were static. I underestimated the dynamic nature of filming individuals in their home settings. My initial plan was to favour a fixed camera (located on a tripod in one area of the room), as this tends to be less intrusive than a moving camera (Heath et al., 2010). I had also planned to be out of sight, retreating to a corner and discreetly moving the camera should the action change locations. Yet during the actual visits this strategy proved impossible. Filming lived experience required dynamic, active interactions and movements on my part. The following excerpt from my journal notes describes an interaction with a participant that illustrates the impossibility of retreating from the research space.

It was my first filming session. Rebecca and Molly were both sitting in the living room the entire time, and this made filming easy. I set up the camera on the tripod and left it in the corner for one hour. I sat with them in the living room, and at first Rebecca tried to make conversation with me. I suggested going into another room, in order that she should continue with her regular activities. She said "no, it's ok, stay". So I sat on the couch while she and her mother talked, the camera running. (Journal notes, 6 April 2011).

Rather than leaving the camera on a tripod and making myself inconspicuous, I was frequently in the heart of quick-moving action. During most visits, I had 
to hold the camera in my hand and move swiftly alongside the caregiver, trying to capture as much action as possible. Even when there was little interaction between the caregiver and care receiver, the caregiver would often walk from one room to another, doing chores. In such instances of frequent movement, my focus was on following the action; the camera was like an extension of, or complement to, my own vision. Even when I was looking through the camera lens, I was part of the dynamic movement and creation of the scene.

Echoing Pink's (2012) argument that places are produced through the collaborative, empathic and embodied engagement of the researcher, as well as Gabb's (2010) explanation that the researcher naturally becomes embedded in family settings, my presence in the homes of the dyads contributed to the creation of the research space. For example, my embodied awareness of heat, smells and sounds affected the way I moved with the camera. This embodied awareness led to an enhanced visceral understanding of the environment that in turn contributed to deeper analysis, as well as to the moment to moment choices of where I set up the camera and how I filmed. For example, during moments of non-moving action, a hot summer sun might compel me to place the camera in the shade, hence determining the angle of the shot. During moving action, I might need to walk around someone in the periphery of the scene, hence compromising the best angle for the shot. The following journal note recounts a scene of everyday interactions during filming. When I later re-watched such scenes I was able to place myself back in these moments and re-experience them through embodied memory.

There was a lot of action throughout the entire hour. This is exactly what I needed and wanted to film. I was there when Rebecca got her mother out of bed and took her to the washroom, when they were preparing breakfast, rescheduling their day and running around. I was hurrying alongside them, with no time to check the angles or worry about getting good shots. It was extremely hot and everyone was sweating. All the windows were open and the curtains were down, making the space somber. I tried to stay in the shade but I also had to be moving. (Journal notes, 22 July 2011).

Had I remained either behind the camera, or in another room while the camera was filming, the data collection would have been incomplete. The camera alone could not capture the entirety of a scene, but only one angle. The fact that I moved with, and was an integral part of, the action meant that I captured valuable observations that would not otherwise have been visible. For example, while the camera may have only captured the back of the caregiver's head, I was able to note her facial expression or her glance at a family member standing in the periphery. The following journal note describes a scene in which there was significant peripheral action that the camera did not capture. In this instance, multiple family members are actively avoiding the camera's frame, yet they are joking about it at the same time. This brings forth the ways in which the camera contributed to my shifting status as both insider and outsider, both friendly presence and intruder. The family members did not mind seeing me; it was the camera that was considered 
unwelcome. Yet had I been in the home without camera equipment, I would not have witnessed this family cohesiveness in the goal of protecting their intimacy.

The session took place at night; I arrived at 9:00pm. I was tired. When I walked in the whole family was in the living room watching a movie. Rebecca's children jokingly said "oh no" when I walked in, because they don't like the camera. I talked to Rebecca for a few minutes before filming. I began filming as Rebecca started Molly's bedtime routine. The rest of the family stayed in the living room at first, but then came in and out of the kitchen, just being careful to avoid the camera. (Journal notes, 6 August 2011).

Despite the participants' hesitant reactions to the camera, I was nonetheless invited into the dyads' homes in a way that went far beyond the role of an observer and videographer. While it is common for researchers to be drawn into a larger participatory role than expected (DeWalt and DeWalt, 2011), I was nonetheless surprised and initially unprepared for this development. During quiet moments, the caregivers often engaged me in conversation and I responded in a friendly manner. The caregivers would inform me of what had happened in their lives since the last visit, or talk to me about how they were feeling. This may have been in part the result of social pressure to make conversation, yet the seemingly genuine need to talk also spoke to the social isolation that can accompany home caregiving. My shifting roles as observer, videographer and friendly visitor paralleled the shifting and overlapping forms of information that were collected throughout the project. As I discuss in the following section, the process of knowledge creation was based on information from the camera, the dyads, my own subjective choices and feelings, and ultimately from the interactions between all these elements.

\section{Overlapping layers of information}

Whereas all research is a co-construction between the researcher, the participants and the environment (Pink, 2015), in the case of videography the camera becomes an additional player, creating yet another perspective of a scene. In the case of the current project, three levels of information were produced, which together formed a holistic portrait of the action: what was actually being said and done in the moment: what the camera captured of the scene (determined by where I placed the camera and how I shot the scene), my embodied and visceral reactions as a participant in the scene and what I later retained of these moments. For example, during a visit with Susan and her husband, the camera was directed towards the caregiver's face as she was speaking. She was recounting how her husband was less active than he used to be and how he was slow to get going in the morning. Yet on the other side of the room, just outside the range of the camera, Susan's husband was in the process of exercising with his personal trainer. The care receiver's repetitive and energetic movements were in juxtaposition to his wife's description of his sluggishness, which begs the question as to whether Susan was so consumed by the losses and 
decline in her husband that this coloured her entire vision. This striking juxtaposition was visible only from my vantage point, as the camera did not apprehend the entirety of this scene and the richness of the dynamic relationship between talk and movement. Had I not also been observing along with the camera, I would not have captured this information about Susan's perception of her husband and his illness.

This multi-layered evidence came to light most fully when I began to watch and rewatch the footage and analyse it in relation to my own experience of the action. After each filming session, I watched the hour of footage in its entirety and made a $\log$ of the main elements that occurred in the filming session. I then rewatched the same footage numerous times and selected key scenes that conveyed physical and emotional interactions between the dyads, possible incongruity, gestures of fatigue or difficulty, or simply moments of everyday movement. I transcribed these small scenes of footage according to conversation analysis notation (Sacks et al., 1974) that captured verbal details normally considered banal, such as pronunciation, emphasis, intonation, and pauses (Liddicoat, 2011). From these verbal transcriptions, I added detailed information about the visual action using written description. For each chosen scene, I had a final document that contained a transcription of all the action, both verbal and nonverbal. However, even such a detailed transcription did not recount the full story. The coding and interpretive process emerged only when I had looked at these transcripts side by side with my journal notes, analytic memos and memories. I was then able to winnow this raw and partially processed data into meaning units (Creswell, 2013), and develop these preliminary themes into a larger, overarching analysis.

The following scene, a typical domestic interaction between the caregiver Rebecca and her mother, provides an example of the interplay between the detailed transcription of the verbal and nonverbal action (the verbal action is written according to conversation analysis notation), and the excerpts from my journal notes and analytic memos. I comment on the camera position and where I was physically located during the scene. Taken together, these various elements provide a portrait of how the various layers of information came together and how my physical, social and emotional location determined what I saw and how I interpreted the scene.

\section{Verbal and nonverbal transcription}

Rebecca: <Laundry >

Rebecca walks into living room with both hands around a laundry basket overflowing with clothes. She walks towards armchair and turns around.

(6) Ohhh(sigh)

She bends all the way forward and places basket on floor.

(2) Never stops eh Mom?

Rebecca remains bent over the basket; both hands pick up some pieces of clothing on top. Her gaze is down.

Molly (care receiver): ${ }^{\circ}$ Nope ${ }^{\circ}$.

Rebecca stands up, facing Molly, with a piece of clothing in hand. 


\section{Rebecca: Oh and your nice-}

Rebecca holds a piece of clothing in both hands, patting and pulling a few times with both hands.

\section{(.) These are nice and toasty warm now,}

Rebecca slides her right hand inside the slipper and moves hand right to the end and pushes her fingers around like it's a puppet. She is facing Molly, her gaze directed at Molly.

\section{Rebecca: hhhhhhh....(exhale sigh)}

Rebecca bends forward and to the right, and throws slipper into a bag (camera cannot see facial expression).

(3) OK:

Rebecca stands up straight. She raises both hands to tuck hair behind her ears. She then bends completely over the basket again.

\section{(2) ahhhh (sigh)}

Camera position: Camera is on a tripod in the corner of the room.

Journal note: It was my first filming session with Rebecca and Molly. They were both in the living room the entire time, and this made filming easier. I set up the camera on the tripod and left it in the corner for one hour. I sat on the couch in the corner, just out of view of the camera lens. I was observing the action and later Rebecca started including me in the conversation.

Analysis note: The women caregivers are constantly doing work that is gendered in nature - cooking, laundry and cleaning. Would any caregiver be doing this out of necessity, or is it particular to women?

This type of multi-layered transcript, which brings forth multiple perspectives of one scene, can be pertinent for all videographic research, in particular studies that examine the embodied, everyday aspects of life. While this type of transcript is time consuming to create (as is the in-depth nature of the method itself), and can only be produced for a select number of scenes, it contributes to a more comprehensive analysis. Instead of written description of the action, still frames from the video footage can also be inserted next to the verbal transcription. Seeing the actual images side by side with other transcribed elements can bring additional intimacy to our understanding of the participants' realities (Russell and Diaz, 2013).

\section{Conclusion}

This paper, which has recounted my experience conducting video-based microethnographic research in caregivers' homes, builds on literature in the field of visual methods by demonstrating from an inside perspective how reflexivity can be used as a research tool. It has also highlighted the links between reflexivity and ethical decisions in the field during film based data collection. While videographic work is often perceived as 'objectively' empirical as others can scrutinize the footage, examine the images, and justify or dispute interpretive claims (LeBaron, 2008), the scenes described throughout this paper illustrate how the creation and interpretation of the footage is shaped through the subjective, embodied lens of the 
researcher. This contribution of the researcher's lived experiences is as valuable to the process of knowledge creation as the empirical data itself.

The paper has also raised questions for all video based research that aims to analyse the everyday lives of individuals. How far do we go in witnessing the lives of others? Where do we draw the line between the goals of a project and the privacy of the participants? How do we locate our comfort level within the lives of the research participants? Knoblauch et al. (2006) frame such questions as the conflict between the freedom of individuals which contains limits and restrictions, and the freedom of research which is limitless. Yet the literature on video methods has been slow to address these tensions. For example, Heath et al.'s guide to video research (2010) addresses questions of informed consent in diverse settings, but does not comment on ethical decisions during the actual filming.

Answers to ethical tensions can be located in part in the broader literature on self-reflexive qualitative methods, which emphasizes the benefits of reflexivity for creating transparency throughout the research process (Etherington, 2007). Warin's (2011) concept of ethical mindfulness, which builds on Guillemin and Gillam's (2004) concept of an ethics in practice, offers a way forward in its emphasis on the relational sensitivity and self-awareness of the researcher for resolving everyday ethical dilemmas. Gabb's (2010) emphasis on the importance of ongoing consent through the establishment of a trusting relationship between researcher and participant offers another means of viewing moment-to-moment ethical challenges. There is a need to apply these concepts specifically to the context of video based research. Further discussion is needed around the procedures, experiences and ethical tensions of using video as a data collection tool, and these discussions must include the role of the researcher in the filming process.

\section{Declaration of conflicting interests}

The author(s) declared no potential conflicts of interest with respect to the research, authorship, and/or publication of this article.

\section{Funding}

The author(s) received no financial support for the research, authorship, and/or publication of this article.

\section{References}

Bull P (2002) Communication Under the Microscope: The Theory and Practice of Microanalysis. New York, NY: Routledge.

Campos B, Graesch A, Repetti R, et al. (2009) Opportunity for interaction? A naturalistic observation study of dual-earner families after work and school. Journal of Family Psychology 23(6): 798-807.

Canada Public Works and Government Services (2005) Tri-council Policy Statement: Ethical Conduct for Research Involving Humans. Ottawa: Canadian Institutes of Health Research Natural Sciences and Engineering Research Council of Canada Social Sciences and Humanities Research Council of Canada. 
Creswell JW (2013) Qualitative Inquiry and Research Design: Choosing among Five Traditions. 3rd ed. Thousand Oaks, CA: Sage.

DeWalt K and DeWalt B (2011) Participant Observation: A Guide for Fieldworkers. 2nd ed. Plymouth, UK: AltaMira Press.

England K and Dyck I (2011) Managing the body work of home care. Sociology of Health and Illness 33: 206-219.

Erickson F (1996) Ethnographic microanalysis. In: McKay SL and Hornberger N (eds) Sociolinguistics and Language Teaching. Cambridge: Cambridge University Press.

Etherington K (2007) Ethical research in reflexive relationships. Qualitative Inquiry 13(5): 599-616.

Gabb J (2010) Home truths: Ethical issues in family research. Qualitative Research 10(4): 461-478.

Guillemin M and Gillam L (2004) Ethics, reflexivity, and "ethically important moments" in research. Qualitative Inquiry 10(2): 261-280.

Goffman E (1959) The Presentation of Self in Everyday Life. New York, NY: Anchor Books.

Heath C, Hindmarsh J and Luff P (2010) Video in Qualitative Research: Analysing Social Interaction in Everyday Life. London: Sage Publications.

Hurdley R and Dicks B (2011) In-between practice: Working in the 'third space' of sensory and multimodal methodology. Qualitative Research 11(3): 277-292.

Intrieri R and Morse JM (1997) A sequential analysis of verbal and nonverbal interaction of two long-term care residents. Journal of Applied Gerontology 16(4): 477-494.

Knoblauch H and Schnettler B (2012) Videography: Analysing video data as a 'focused' ethnographic and hermeneutical exercise. Qualitative Research 12(3): 334-356.

Knoblauch H, Schnettler B and Raab J (2006) Video-analysis - Methodological aspects of interpretative audiovisual analysis in social research. In: Knoblauch H, Schnettler B, Raab J, et al. (eds) Video Analysis: Methodology \& Methods. Qualitative Audiovisual Data Analysis in Sociology. Frankfort: Peter Lang International Academic Publishers, pp. 9-24.

Knoblauch H and Tuma R (2011) Videography: An interpretative approach to videorecorded micro-social interaction. In: Margolis E and Pauwels L (eds) The Sage Handbook of Visual Research Methods. London: Sage, pp. 414-430.

LeBaron C (2008) Microethnography. In: Donsbach W (ed.) The International Encyclopedia of Communication. Cambridge: Blackwell.

Liddicoat AJ (2011) An Introduction to Conversation Analysis. New York, NY: Continuum International Publishing Group.

Lincoln Y and Guba E (1985) Naturalistic Inquiry. Beverly Hills, CA: Sage.

Lofland J and Lofland L (1995) Analyzing Social Settings: A Guide to Qualitative Observation and Analysis. 3rd ed. Belmont, CA: Wadsworth.

Lomax H, Fink J, Singh N, et al. (2011) The politics of performance: Methodological challenges of researching children's experiences of childhood through the lens of participatory video. International Journal of Social Research Methodology 14(3): 231-243.

Luff P and Heath C (2012) Some "technical challenges" of video analysis: Social actions, objects, material realities and the problems of perspective. Qualitative Review 12: 255-279.

Mannay D and Morgan M (2014) Doing ethnography or applying a qualitative technique? Reflections from the 'waiting field'. Qualitative Research. DOI: 10.1177/1468794113517391.

Mannay D (2010) Making the familiar strange: Can visual research methods render the familiar setting more perceptible? Qualitative Research 10(1): 91-111.

Mondada L (2006) Video recording as the reflexive preservation and configuration of phenomenal features for analysis. In: Knoblauch H, Schnettler B, Raab J, et al. (eds) Video 
Analysis: Methodology \& Methods. Qualitative Audiovisual Data Analysis in Sociology. Frankfort: Peter Lang International Academic Publishers, pp. 51-67.

Ochs E and Kremier-Sadlick T (eds) (2013) Fast forward family: Home, work and relationships in middle class America. Berkeley, CA: University of California Press.

Padgett D (2008) Qualitative Methods in Social Work Practice. 2nd ed. Thousand Oaks, CA: Sage.

Pink S (2015) Doing Sensory Ethnography. 2nd ed. London: Sage.

Pink S (2012) Situating Everyday Life. London: Sage.

Pink S (2011) Multimodality, multisensoriality and ethnographic knowing: Social semiotics and the phenomenology of perception. Qualitative Research 11(3): 261-276.

Pink S (2007) Doing Visual Ethnography. 2nd ed. London: Sage.

Richardson M (2013) Embodied intergenerationality: Family position, place and masculinity. Gender, Place \& Culture: A Journal of Feminist Geography. DOI: 10.1080/ 0966369X.2013.855710.

Russell AC and Diaz N (2013) Photography in social work research: Using visual image to humanize findings. Qualitative Social Work 12(4): 433-453.

Sacks H, Schegloff E and Jefferson G (1974) A simplest systematics for the organization of turn-taking for conversation. Language 50(4): 696-735.

Saxbe D and Repetti RL (2008) Taking the temperature of family life: Preliminary results from an observational study. In: Marcus-Newhall A, Halpern D and Tan S (eds) The Changing Realities of Work and Family: A Multidisciplinary Approach. New York, NY: Wiley-Blackwell, pp. 175-193.

Scherer KR and Ekman P (1982) Methodological issues in studying nonverbal behavior. In: Scherer KR and Ekman P (eds) Handbook of Methods in Nonverbal Behavior Research. Cambridge: Cambridge University Press.

Silverman M (2015) Observing women caregivers' everyday experiences: New ways of understanding and intervening. Journal of Gerontological Social Work 58(2): 206-222.

Silverman M (2013) Sighs, smiles, and worried glances: How the body reveals women caregivers' lived experiences of care to older adults. Journal of Aging Studies 27(3): 288-297.

Stivers T and Sidnell J (2005) Introduction: Multimodal interaction. Semiotica 156: 1-20.

Streeck J, Goodwin C and LeBaron C (2011) Embodied interaction in the material world: An introduction. In: Streeck J, Goodwin C and LeBaron C (eds) Embodied Interaction: Language and Body in the Material World. Cambridge: Cambridge University Press, pp. 1-28.

Streeck J and Mehus S (2005) Microethnography: The study of practices. In: Fitch K and Sanders R (eds) Handbook of Language and Social Interaction. London: Lawrence Erlbaum Associates, pp. 381-404.

Ward R and Campbell S (2013) Mixed methods to explore appearance in dementia care. Dementia 12(3): 337-347.

Warin J (2011) Ethical mindfulness and reflexivity: Managing a research relationship with children and young people in a 14-year qualitative longitudinal (QLR) study. Qualitative Inquiry 17(9): 805-814. 